\title{
Registro de mangue em um sambaqui de pequeno porte do litoral sul de Santa Catarina, Brasil, a cerca de 4900 anos cal BP, e considerações sobre o processo de ocupação do sítio Encantada-III
}

\author{
Rita Scheel-Ybert * \\ Gina Faraco Bianchini * \\ Paulo De Blasis * *
}

RITA SCHEEL-YBERT, R.; BIANCHINI, G.F.; DE BLASIS. P. Registro de mangue em um sambaqui de pequeno porte do litoral sul de Santa Catarina, Brasil, a cerca de 4900 anos cal BP, e considerações sobre o processo de ocupação do sítio EncantadaIII. Revista do Museu de Arqueologia e Etnologia, São Paulo, 19: 103-118, 2009.

Resumo: Fragmentos carbonizados de lenho de Avicennia sp, espécie típica e exclusiva do ecossistema de mangue, foram encontrados em sedimentos arqueológicos datados em cerca de 4900 anos BP no sambaqui Encantada-III, município de Jaguaruna, Estado de Santa Catarina. Este sítio se localiza ligeiramente ao sul do limite atual de distribuição do mangue, cujo desaparecimento desta região está provavelmente associado à variação do nível relativo do mar. Estes resultados corroboram a estreita associação entre grupos sambaquieiros e o manguezal e apresentam evidências diretas da ocorrência deste tipo de vegetação na própria área de implantação do sítio, assim como do uso de madeira de mangue como combustível em sambaquis desta região. Além disso, os dados antracológicos apontam para a existência de dois períodos de ocupação no sítio, provavelmente de curta duração, sem evidências de atividades cotidianas, sendo o primeiro associado a populações sambaquieiras e o segundo, possivelmente, a populações Je ou Guarani, que ocuparam a área posteriormente.

Palavras-chave: Sambaquis - Antracologia - Mangue - Paleoambiente Holoceno - Litoral sul brasileiro.

\section{Introdução}

A associação de populações sambaquieiras com o ambiente de mangue é reco- nhecida de longa data. Conchas de ostras, pinças de caranguejos e restos de aves associadas a este ambiente estão presentes na maioria dos sítios estudados até o momento, sendo
(*) Museu Nacional, Universidade Federal do Rio de Janeiro. Departamento de Antropologia. <scheelybert@mn.ufrj.br>; <ginabianchini@ufrj.br> $\left.{ }^{(* *}\right)$ Museu de Arqueologia e Etnologia, Universidade de São Paulo.<deblasis@usp.br> 
Registro de mangue em um sambaqui de pequeno porte do litoral sul de Santa Catarina, Brasil, a cerca de 4900 anos cal BP, e considerações sobre o processo de ocupação do sítio Encantada-III.

Revista do Museu de Arqueologia e Etnologia, São Paulo, 19: 103-118, 2009.

frequentes em sambaquis de diversas partes da costa brasileira e de diversos períodos de tempo. A importância deste ambiente como provedor de recursos alimentares abundantes, concentrados e de fácil obtenção fez dele um elemento privilegiado no modo de vida sambaquieiro.

Reconstituições paleoambientais baseadas na antracologia realizadas em diversos sambaquis do sudeste do Estado do Rio de Janeiro comprovaram que o mangue fazia parte do ambiente no qual viviam estas populações, que se instalavam preferencialmente no ecossistema de restinga, mas tendo sempre à proximidade manguezais e florestas costeiras (Scheel-Ybert 1999, 2000, 2001; Scheel-Ybert et al. 2003; Scheel-Ybert \& Dias 2007).

O manguezal é um ecossistema costeiro, de transição entre os ambientes terrestre e marinho, sujeito ao regime de marés. Pode ser definido como uma floresta de árvores xerófilas adaptadas a um substrato lamoso constantemente úmido, pouco oxigenado, com forte taxa de salinidade e periodicamente inundado (Schaeffer-Novelli et al. 2000). Ocorre em regiões costeiras abrigadas e apresenta condições propícias para alimentação, proteção e reprodução de muitas espécies animais, sendo justamente isto o que o torna tão importante para diversas populações humanas.

Atualmente, os manguezais se distribuem essencialmente na zona intertropical. Até a expansão da ocupação pós-colonial, esta vegetação ocupava uma grande extensão das costas brasileiras, assim como as margens de diversas lagunas e rios litorâneos. Nas costas orientais da América, sua área de ocorrência se estende das ilhas Bermudas (32०25' de latitude norte) a Laguna, no Estado de Santa Catarina (28'30' de latitude sul) (Schaeffer-Novelli et al. 2000). Devido às condições extremamente restritivas deste ambiente, o número de espécies bem adaptadas é reduzido. As principais espécies de mangue pertencem aos gêneros Rhizophora, Avicennia e Laguncularia. Ocorrem também espécies associadas, como Hibiscus pernambucensis, Conocarpus erectus, Caesalpinia bonduc, Annona glabra, Dalbergia ecastophyla, entre várias outras plantas lenhosas e herbáceas
(Silveira 1937), além de macro e micro-algas, todas adaptadas a flutuações de salinidade. Apesar da diversidade florística limitada, os manguezais brasileiros apresentam uma grande diversidade estrutural, de formas de crescimento e de padrões de distribuição de espécies (Schaeffer-Novelli et al. 1990).

As espécies do gênero Avicennia são as mais tolerantes à salinidade, Rhizophora é o gênero menos tolerante e Laguncularia se situa entre os dois extremos (Cintrón-Molero \& SchaefferNovelli 1992). Um mangue com forte predominância de Avicennia indica um ambiente árido, isto é, de salinidade muito elevada (Blasco 1987).

Cinco condições básicas são postuladas para a ocorrência de manguezais, embora nem todas precisem necessariamente ser atendidas: (1) temperaturas tropicais; (2) costas livres da ação de vagas e marés violentas; (3) presença de água salgada, assim como de uma fonte de água doce; (4) solos hidromorfos anóxicos, finoparticulados (substrato frouxo constituído por silte e argila fina, rico em matéria orgânica); (5) larga amplitude de marés (Walsh 1974).

Além da presença de fontes de água salgada e de água doce, o clima é o principal fator limitante à ocorrência deste ecossistema. Esta vegetação depende de temperaturas médias sempre acima de $20^{\circ} \mathrm{C}$; média das temperaturas mínimas superior a $15^{\circ} \mathrm{C}$; amplitude térmica anual menor que $5^{\circ} \mathrm{C}$; e precipitação acima de $1500 \mathrm{~mm} /$ ano, sem períodos prolongados de seca. Os manguezais apresentam grande adaptabilidade quanto ao tipo de solo, taxa de salinidade e amplitude das marés, podendo inclusive tolerar uma pluviosidade inferior a $1500 \mathrm{~mm}$ anuais. No entanto, calor e luminosidade são fundamentais, o que inviabiliza sua ocorrência fora da zona intertropical.

\section{Área de estudo}

A área de estudo, inserida no quadro do projeto "Sambaquis e Paisagem: modelando a inter-relação entre processos culturais e naturais no litoral sul de Santa Catarina", coordenado por Paulo De Blasis (MAE-USP), abrange parte 
dos municípios de Jaguaruna, Laguna e Tubarão, no entorno das Lagunas do Camacho e Garopaba do Sul, região que apresenta potencial arqueológico significativo em função do grande número de sítios aí instalados (De Blasis et al. 1998, 2007). A área, bastante aplainada, configurava uma antiga baía ampla e aberta à época do máximo transgressivo que, desde então, vem sendo progressivamente assoreada, resultando na paisagem lagunar que aparece na Figura 1.

O foco deste projeto é o estudo dos padrões de ocupação pré-colonial da região ao longo do Holoceno e sua relação com a dinâmica da paisagem no litoral sul de Santa Catarina. O presente artigo se refere à análise de amostras provenientes de um sambaqui de pequeno porte denominado Encantada-III (também conhecido como Juventus), situado na localidade de Garopaba do Sul, município de Jaguaruna (2837'37"S, 48॰54'52"W) (Fig. 1).

O clima atual da região, que sofre influência marítima e está condicionado ao relevo local, é do tipo Cfa-Subtropical, mesotérmico úmido com verão quente (IBGE 2002). As temperaturas médias máximas dos meses mais quentes (dezembro a março) são acima de $25^{\circ} \mathrm{C}$. A temperatura média mínima dos meses mais frios fica em torno de $13{ }^{\circ} \mathrm{C}$. A precipitação média anual é de $1450 \mathrm{~mm}$; os maiores índices de precipitação ocorrem em março e setembro, chegando próximo a 150 $\mathrm{mm}$. A umidade relativa média anual é de $82 \%$, com valores próximos de $85 \%$ no mês de setembro. A estação seca vai de outubro a janeiro, quando diminuem os índices de precipitação e aumenta a evaporação total (SDM 2002).

A vegetação da área de estudo está atualmente bastante degradada, com forte influência de formações secundárias devida à atividade antrópica. A vegetação primitiva se caracteriza pela presença de duas associações vegetais principais que se distinguem florística e fitossociologicamente, distribuindo-se de acordo com um gradiente altitudinal: a Restinga, sobre a planície costeira, e a Floresta Atlântica, em áreas de topografia mais acentuada (Klein 1978).

\section{Material e métodos}

O sambaqui Encantada-III é um sítio pequeno, medindo 34 metros de comprimento por 15 metros de largura e 2 metros de altura (Fig. 2). Localiza-se às margens de uma área inundável, distante cerca de $1400 \mathrm{~m}$ do mar e $850 \mathrm{~m}$ da lagoa Garopaba do Sul, em uma zona de confluência do sistema de barra-barreira com formações dunares estabilizadas (Giannini 1993, 1998, 2002; Giannini et al. 2005, 2007).

Sua configuração estratigráfica se caracteriza por uma estreita camada de sedimento conchífero enegrecido, com no máximo $40 \mathrm{~cm}$ de espessura no topo, diluindo-se paulatinamente em direção à periferia rebaixada do sítio (Fig. 3). Esta camada se encontra assentada sobre o que se considerou, em um primeiro momento, uma duna. No entanto, a morfologia, estruturação interna e modo de ocorrência desta "duna" não correspondem àquelas de feições eólicas conhecidas na região, o que indica que ela própria é uma estrutura construída, tal qual a camada que a recobre (Giannini et al., em preparação). Esta estrutura estratigráfica, vista com surpresa neste sítio, onde foi detectada pela primeira vez, revelou-se um padrão bastante comum, ocorrendo em diversos outros sambaquis de pequenas proporções identificados na região nos últimos anos.

As amostras antracológicas analisadas foram coletadas a partir de um perfil de 200 x $50 \mathrm{~cm}$ escavado na parte mais alta do sítio em 2003 (Fig. 3). A camada que recapeia o sítio é constituída por uma matriz escura argilo-arenosa com conchas geralmente bastante fragmentadas, quase que exclusivamente de Anomalocardia brasiliensis, com uma forte pátina escura vinda do sedimento. Observamos raríssimos exemplares de Lucina pectinata, inteiros ou fragmentados, e raras outras espécies de bivalves, além de alguns gastrópodes. Nesta camada foram encontrados muito poucos ossos de peixe (alguns queimados), um único fragmento ósseo de fauna terrestre e carvões. Raríssimos são os artefatos líticos (apenas algumas lascas bastante diminutas foram coletadas) e uma única ponta óssea foi encontrada. 
Registro de mangue em um sambaqui de pequeno porte do litoral sul de Santa Catarina, Brasil, a cerca de 4900 anos cal BP, e considerações sobre o processo de ocupação do sítio Encantada-III.

Revista do Museu de Arqueologia e Etnologia, São Paulo, 19: 103-118, 2009.
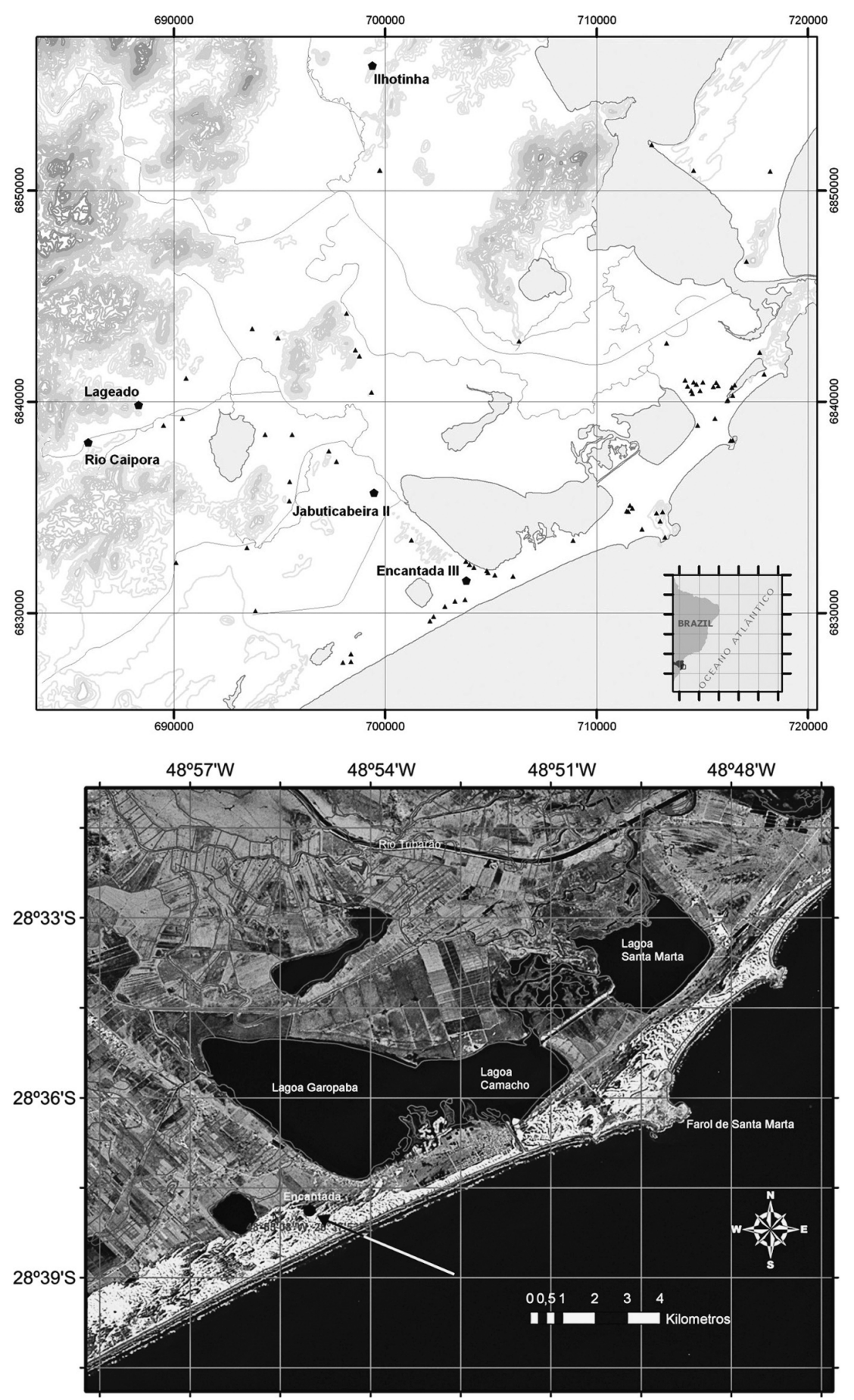

Fig. 1. Localização da área de estudo. Acima, área de pesquisa no sul catarinense, com destaque para o sambaqui Encantada-III (Juventus) e os outros sítios citados no texto. Os demais sambaquis cadastrados na área são representados por triângulos. Cada quadrado das coordenadas UTM tem $10 \mathrm{~km}$ de lado. Abaixo, imagem de satélite evidenciando aspectos físicos da área de implantação do sítio. 


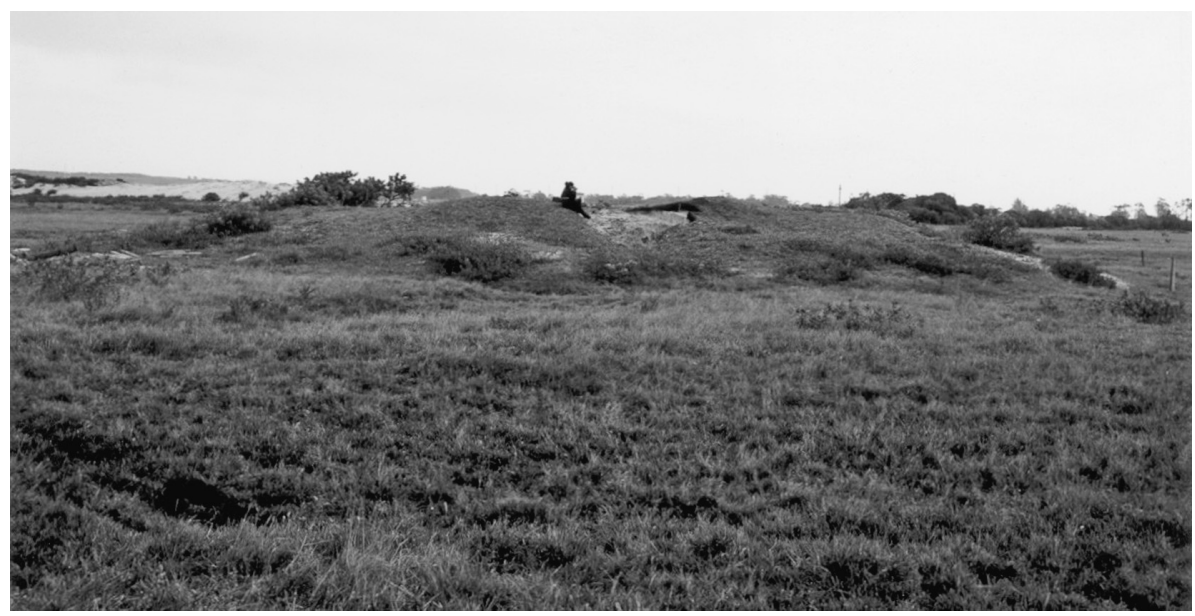

Fig. 2. Aspecto do sambaqui Encantada-III (Juventus) e de sua área de implantação (Foto: Paulo De Blasis).

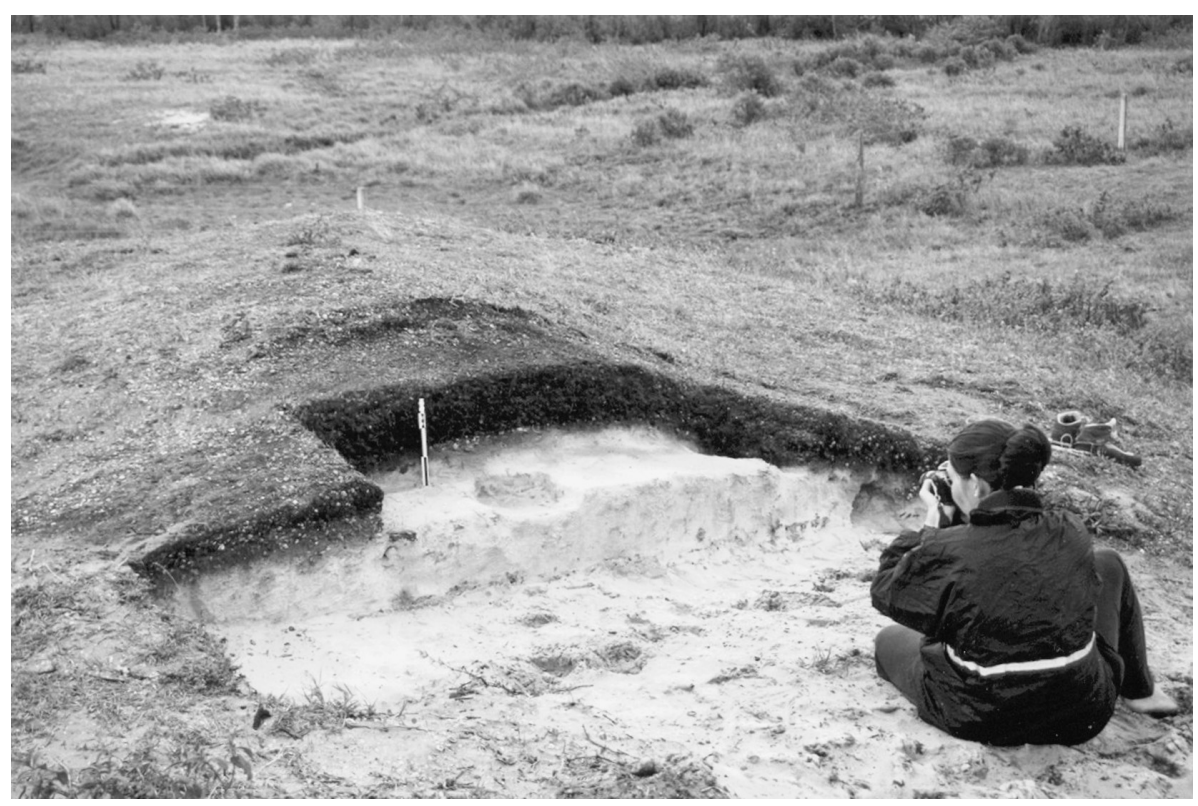

Fig. 3. Aspecto do sambaqui Encantada-III (Juventus), evidenciando o perfil antracológico escavado na camada de sedimento conchífero enegrecido, a camada arenosa subjacente, e a redução da espessura do pacote arqueológico em direção à periferia do sítio (Foto: Paulo De Blasis).

Entre 30 e $40 \mathrm{~cm}$ de profundidade, na camada de contato entre o sedimento escuro e a areia branca da camada subjacente, ocorre em alguns locais uma maior concentração de conchas de Anomalocardia brasiliensis, neste caso sempre inteiras, formando uma espécie de "piso" (Fig. 4).
A amostragem antracológica foi feita segundo níveis artificiais de $10 \mathrm{~cm}$ de espessura e o material coletado foi submetido à flotação durante o trabalho de campo, resgatando-se os carvões para análise antracológica.

No laboratório, cada fragmento de carvão foi quebrado manualmente segundo os três planos fundamentais da madeira, e em seguida 
Registro de mangue em um sambaqui de pequeno porte do litoral sul de Santa Catarina, Brasil, a cerca de 4900 anos cal BP, e considerações sobre o processo de ocupação do sítio Encantada-III.

Revista do Museu de Arqueologia e Etnologia, São Paulo, 19: 103-118, 2009.

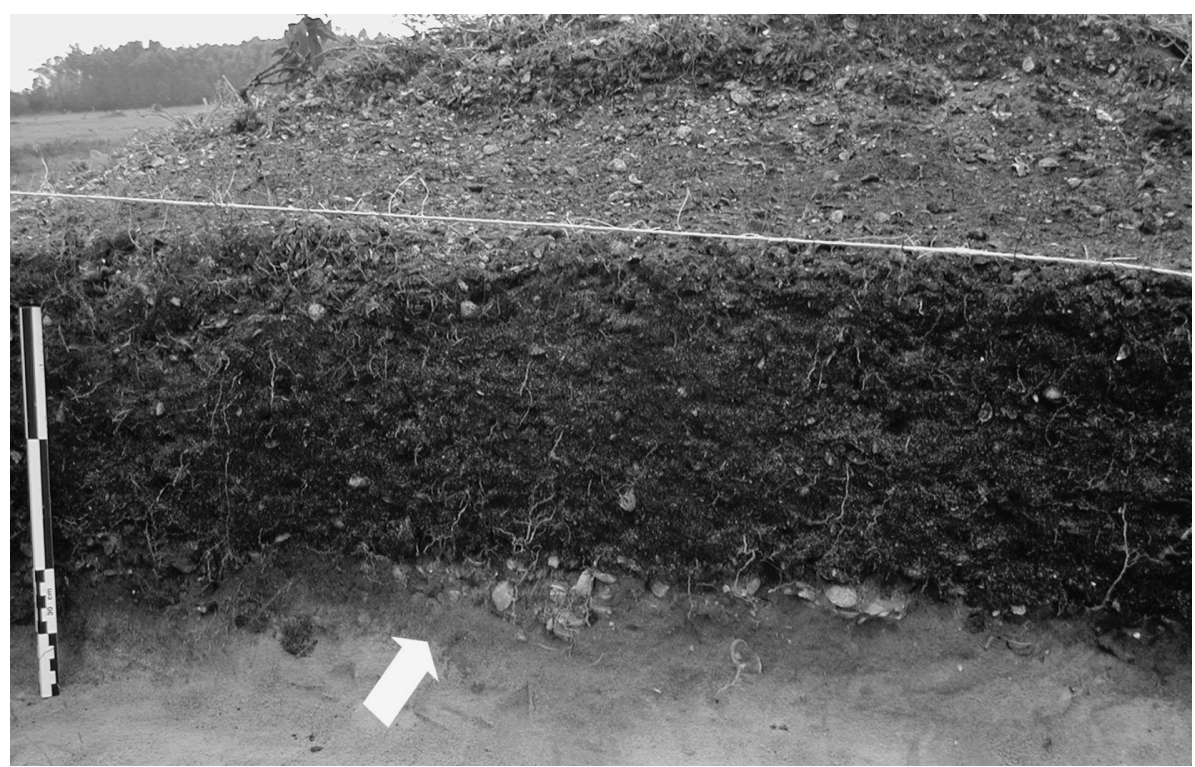

Fig. 4. Acumulação de conchas na camada de contato entre o sedimento escuro e a areia branca da camada de base do sambaqui Encantada-III (Juventus) (Foto: R. Scheel-Ybert).

identificado em microscópio óptico de luz refletida com campo claro e campo escuro. A determinação taxonômica foi feita por comparação exaustiva do fragmento desconhecido com amostras identificadas da coleção de referência de madeiras atuais carbonizadas do Laboratório de Paleoecologia Vegetal do Museu Nacional. Foi utilizado para isso o programa de identificação "Atlas Brasil" (Scheel-Ybert et al. 2006), além de consultas a obras e artigos da literatura.

Datações por AMS foram feitas após o estudo antracológico, o que é possível porque nenhum produto químico é utilizado no processo de identificação dos fragmentos (Vernet et al. 1979). Cada datação foi obtida a partir de carvões de uma única espécie, selecionados durante a análise antracológica.

Todas as datações apresentadas neste texto, inclusive aquelas que já haviam sido publicadas anteriormente, foram calibradas com o uso do programa Calib (Stuiver et al. 2008). No caso de amostras de conchas, utilizou-se a curva Marine04 (Hughen et al. 2004), considerando o valor de efeito reservatório (R) de $220 \pm 20$ anos, conforme proposto por Eastoe et al. (2002).

\section{Resultados}

No total, 265 fragmentos de carvão foram analisados neste sítio, dos quais apenas 169 puderam ser taxonomicamente identificados. A pequena quantidade de fragmentos coletados não está relacionada a um problema amostral, mas sim a uma baixa concentração de carvões no sedimento. O perfil amostrado seguiu dimensões padrão habitualmente utilizadas em amostragens antracológicas (Scheel-Ybert et al. 2005/2006), mas a quantidade de carvões obtida foi muito menor do que o normalmente obtido a partir destas amostragens. Além disso, o tamanho dos fragmentos foi extremamente reduzido, sempre inferior a $2 \mathrm{~mm}$, o que é bastante incomum no caso de amostras de sambaquis. Isto provavelmente está relacionado a uma menor frequência de queimas neste sítio do que o normalmente observado em outros sambaquis.

A alta proporção de indetermináveis, por outro lado, pode ser explicada pelo pequeno tamanho dos fragmentos. Além de dificultar a análise, fragmentos muito pequenos podem reduzir a precisão da determinação taxonômica, pois geralmente não apresentam um conjunto 
suficientemente grande de caracteres anatômicos que autorizem uma boa identificação.

Ainda que devam ser interpretados com cautela, especialmente devido ao pequeno número de fragmentos de carvão encontrados, os resultados da análise antracológica se mostraram interessantes e significativos.

Ao contrário do aspecto macroscópico da matriz arqueológica analisada, na qual nenhuma estratificação interna foi observada, o diagrama antracológico permitiu a identificação de duas zonas claramente definidas (Fig. 5): a zona I, inferior, caracterizada pela presença de mangue (Avicennia sp), de espécies características da mata de restinga (Euphorbiaceae, Pachystroma sp, Melastomataceae, Myrtaceae) e de plantas pioneiras (lianas não identificadas); e a zona II, superior, que não apresenta elementos de mangue, mas sim uma grande proporção de pioneiras (pelo menos três espécies de liana não identificadas), e taxa característicos da mata de restinga (especialmente uma Sapotaceae não identificada, mas também Anacardiaceae, Euphorbiaceae e Myrtaceae) (Fig. 6). Na transição entre estas duas zonas, observa-se o desaparecimento do mangue e o aumento relativo da vegetação de restinga e pioneira.

Além disso, um forte aumento de diversidade ocorre no interior da zona I, entre os níveis $30-40$ e 20-30. O incremento progressivo na variedade de espécies de restinga concomitante ao desaparecimento de Avicennia poderia significar o início do processo de retração do mangue na região, com avanço da mata de restinga. Esta interpretação, no entanto, deve ser tomada com cautela, não só devido ao baixo número de fragmentos disponíveis para análise, como pelo fato de que não se pode afirmar que o mangue tenha de fato diminuído entre as duas amostras, pois o aumento da proporção de outras espécies provoca a diminuição da porcentagem relativa da espécie de mangue, sem que isso signifique necessariamente sua rarefação no ambiente. Uma interpretação alternativa seria a de que tenha havido simplesmente uma variação no uso de espécies de restinga/pioneiras em relação às espécies de mangue em dois eventos de queima (fogueiras) diferentes. Neste caso, a variação observada no interior da zona I seria justificada pela disponibilidade ou escolha diferenciada de lenha para cada um destes eventos, e não por uma variação ambiental.

Uma melhor compreensão do processo de variação ambiental ocorrido na região depende de análises mais detalhadas de um material abrangendo todo o período de tempo em questão, a fim de determinar em que momento, efetivamente, o mangue começou a desaparecer.

Note-se que todos os taxa identificados, com exceção de Avicennia, podem ser encontrados tanto na mata de restinga quanto na Mata Attântica. A sua atribuição à mata de restinga foi feita com base no contexto geográfico do sítio, próximo ao litoral, visto que nesta região a Mata Atlântica normalmente só ocorre mais para o interior e em altitudes um pouco mais elevadas.

A forte proporção de espécies pioneiras, especialmente as lianas não-identificadas, sugere um ambiente de colonização recente ou uma borda de mata. É possível, também, que elas sejam provenientes de um ambiente mais aberto nas proximidades do sítio. Alguns poucos fragmentos de córtex de palmeira que também foram encontrados tendem a corroborar esta hipótese, pois podem ser provenientes de pequenas palmeiras frequentes na restinga aberta e em bordas de lagoa.

É interessante também assinalar a presença, apenas na zona antracológica II, de fragmentos de coquinhos (4), sementes (5) e de parênquima não identificado (2), estes últimos podendo ser originados tanto de sementes quanto de tubérculos (Fig. 7). A maior parte destes restos foi encontrada no nível 0-10, onde totalizam $10 \%$ de todos os fragmentos encontrados; apenas uma semente e um coquinho provêm do nível 10-20, e nenhuma dos outros níveis. $\mathrm{O}$ tamanho extremamente reduzido dos fragmentos impede qualquer tentativa de determinação, não sendo possível sequer afirmar que se trate efetivamente de restos alimentares, mas esta é uma hipótese que deve ser considerada.

A cronologia do sítio foi reforçada com base em datações AMS feitas diretamente a 
Registro de mangue em um sambaqui de pequeno porte do litoral sul de Santa Catarina, Brasil, a cerca de 4900 anos cal BP, e considerações sobre o processo de ocupação do sítio Encantada-III.

Revista do Museu de Arqueologia e Etnologia, São Paulo, 19: 103-118, 2009.

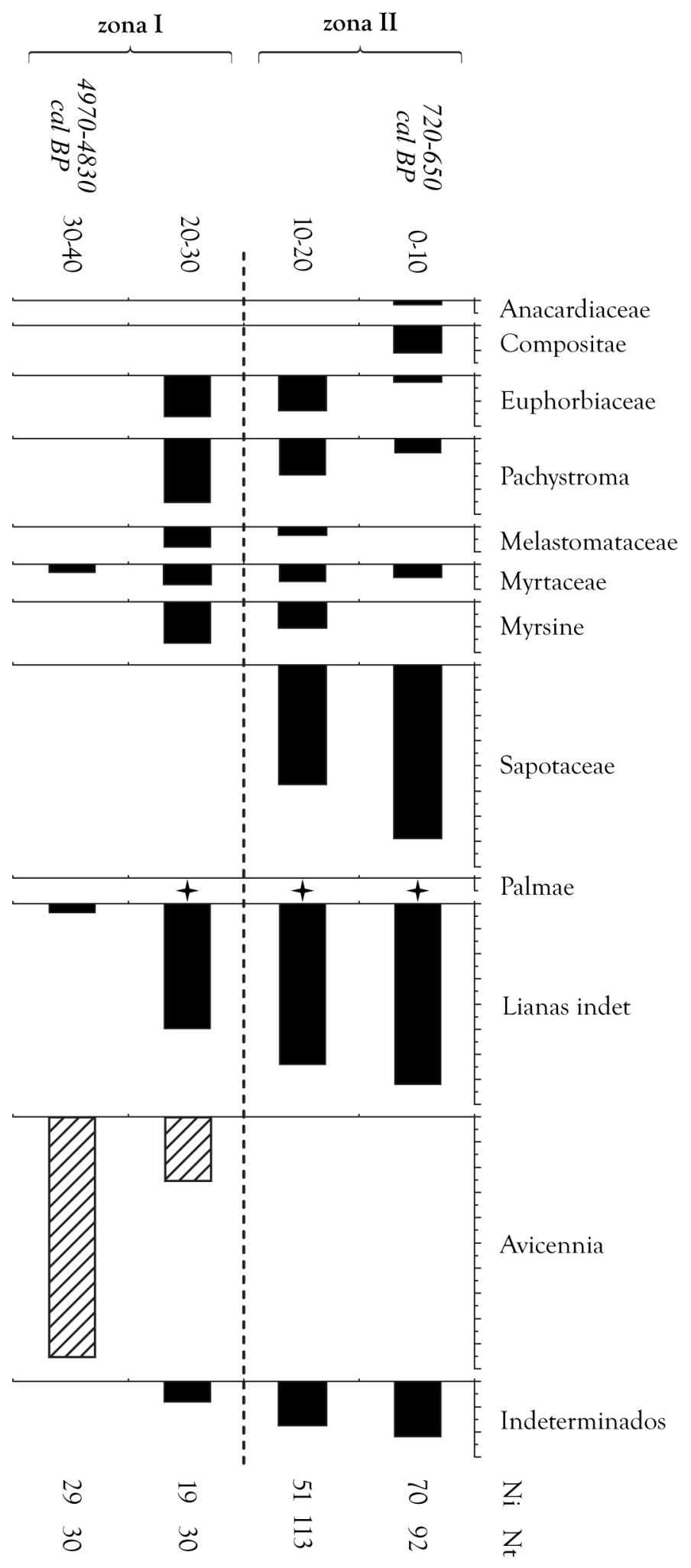

Fig. 5. Diagrama antracológico completo do sambaqui Encantada-III (Juventus), Garopaba do Sul, SC. 

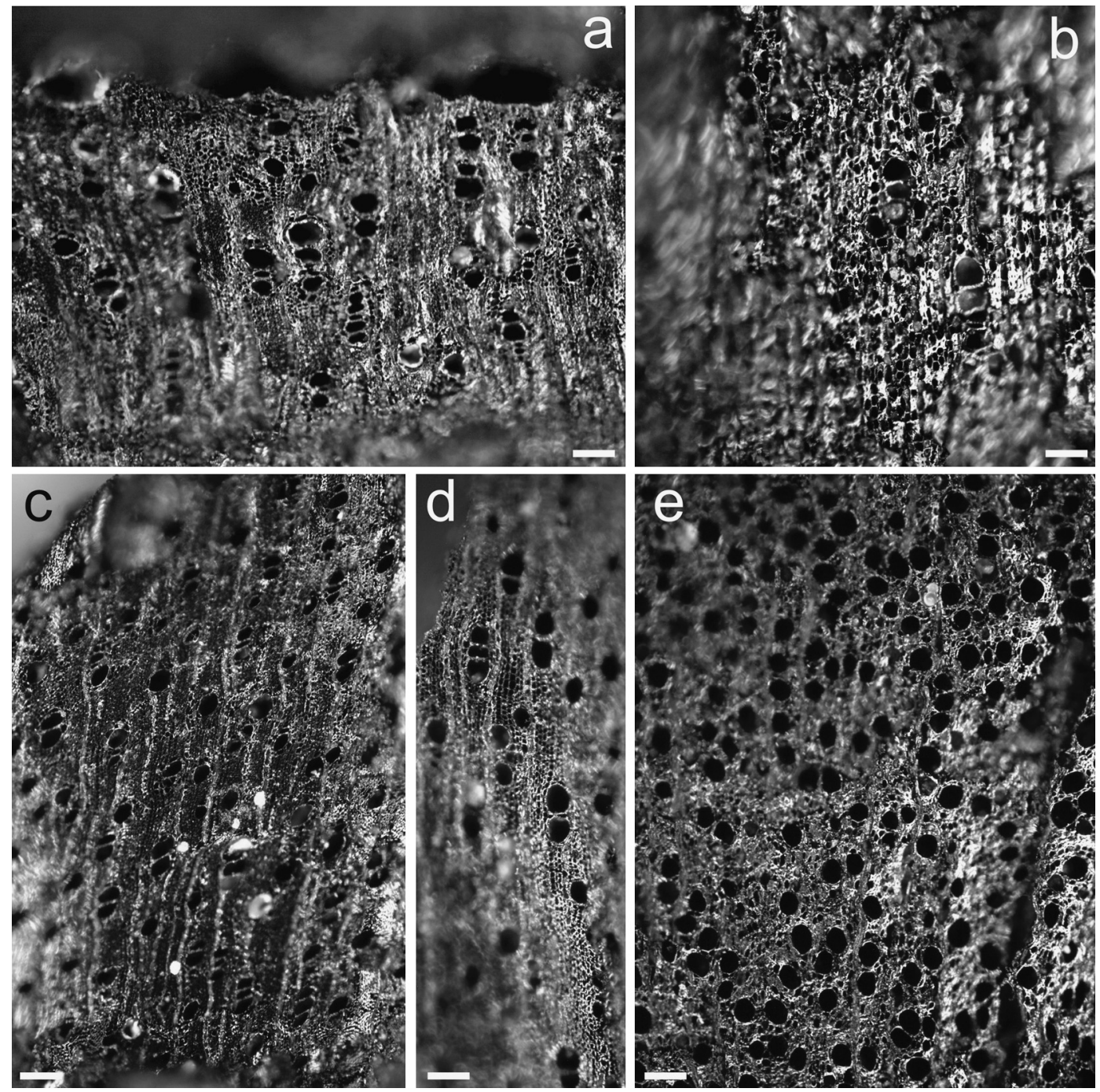

Fig. 6. Espécies lenhosas encontradas no sambaqui Encantada-III (Juventus). (a) Avicennia sp; (b) Sapotaceae; (c) Pachystroma sp; (d) Melastomataceae; (e) Myrtaceae.

partir dos carvões analisados (Tabela I).

Fragmentos de Avicennia sp do nível de base $(30-40 \mathrm{~cm})$ forneceram a idade de $4320 \pm 40$ anos BP (4970-4830 anos cal BP), a qual coincide com a datação de $4420 \pm 50$ anos BP (4961-4642 anos cal BP), obtida anteriormente a partir de uma amostra de conchas de Anomalocardia proveniente da mesma camada, na mesma profundidade (De Blasis et al. 2007). Esta paridade concha/carvão deu consistência a ambas as datações, que se confirmam mutuamente.
Fragmentos de carvão de Sapotaceae provenientes do nível superior, sub-superficial, do sambaqui Encantada-III $(0-10 \mathrm{~cm})$ forneceram uma idade de apenas $740 \pm 40$ anos BP (720-650 anos cal BP). Esta data é muito recente, sendo incompatível com a cronologia regional estabelecida para a ocupação sambaquieira, incluindo vários outros pequenos sambaquis. Deve-se descartar a hipótese de contaminação, pois a datação de fragmentos de carvão de uma única espécie, em particular da espécie dominante, visa justamente limitar o 
Registro de mangue em um sambaqui de pequeno porte do litoral sul de Santa Catarina, Brasil, a cerca de 4900 anos cal BP, e considerações sobre o processo de ocupação do sítio Encantada-III.

Revista do Museu de Arqueologia e Etnologia, São Paulo, 19: 103-118, 2009.
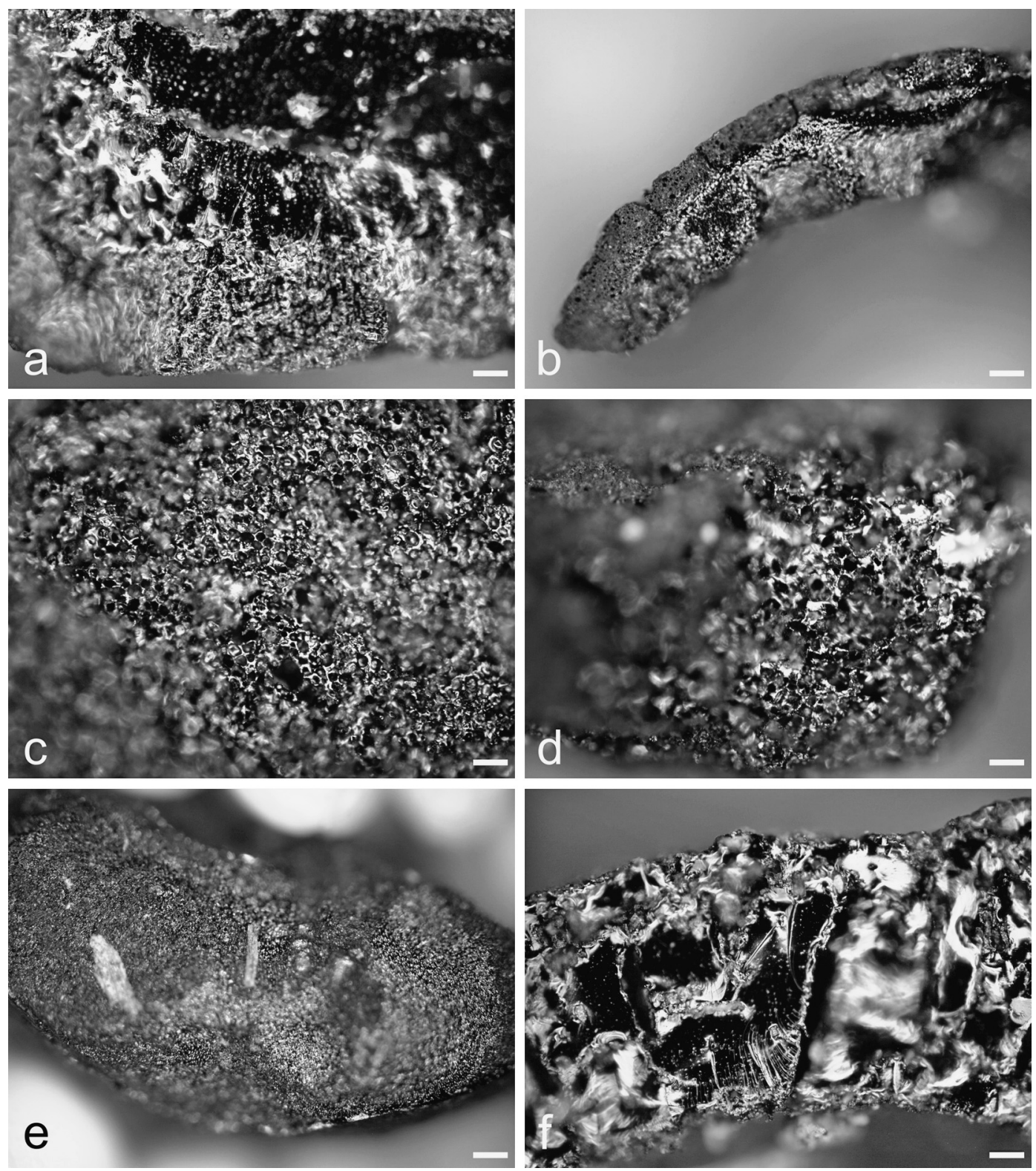

Fig. 7. Vestígios arqueobotânicos não lenhosos provenientes do sambaqui Encantada-III (Juventus). (a,f) coquinhos; (b,e) sementes; (c,d) fragmentos de parênquima não identificado; (a-e) nível 0-10; (f) nível 10-20.

risco de que fragmentos de outros contextos (carvões de outros níveis ou matéria orgânica) se misturem acidentalmente com o material datado. No entanto, é possível que os carvões datados não estejam relacionados com a construção do sambaqui, sendo oriundos de uma queima realizada na superfície do sítio por volta de $750 \mathrm{BP}$.

\section{Discussão}

O sítio Encantada-III dista apenas cerca de $20 \mathrm{~km}$ do limite meridional atual de distribuição do mangue (cf. Schaeffer-Novelli et al. 2000), mas este tipo de vegetação não ocorre mais nesta localidade. O desaparecimento do manguezal na área poderia estar associado a 
Tabela I

\begin{tabular}{|c|c|c|c|c|c|}
\hline \multicolumn{6}{|c|}{ Datações obtidas para o sítio Encantada-III (Juventus)* } \\
\hline Sítio & Proveniência & Data & Sigma & $\begin{array}{c}\text { Data } \\
\text { Calibrada } \\
\end{array}$ & Laboratório \\
\hline & el $\quad 0-10$ & 740 & 40 & $720-650$ & Bet: \\
\hline Encantada - III & nível 30-40, carvão (Avicennia) & 4320 & 40 & $4970-4830$ & Beta 189713 \\
\hline Encantada - III & nível 30-40, concha (Anomalocardia) & 4420 & 50 & 4961-4642 & Az 10638 \\
\hline
\end{tabular}

$\left({ }^{*}\right)$ A datação sobre Anomalocardia já havia sido anteriormente publicada (De Blasis et al. 2007).

fatores climáticos (o clima regional, durante o Holoceno médio, pode ter sido mais quente e úmido do que nos dias atuais), antrópicos (desaparecimento do mangue devido à atividade humana), ou relacionados à variação do nível relativo do mar.

É provável que o Holoceno Médio tenha sido um período mais quente e úmido do que o atual, estando relacionado ao "Ótimo Climático" (Bradley 1999), no entanto ainda existem muito poucos estudos paleoambientais nesta área, especialmente para o período estudado. Na Serra Geral, região centro-sul do Estado de Santa Catarina, análises palinológicas foram realizadas em dois testemunhos entre 1400-1800 m de altitude

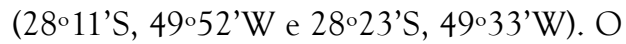
clima local parece ter sido frio e relativamente seco entre 10.500 e 10.000 anos $\mathrm{BP}$, quente e seco entre 10.000 e 3000 anos BP, frio e úmido entre 3000 e 100 anos BP, e mais quente e mais seco desde então (Behling 1995). No entanto, os resultados apresentados por este autor mostram a expansão da Mata Atlântica entre 7800 e 3200 anos BP, o que sugere um aumento de umidade neste período (Ybert et al. 2003). Na planície costeira, dois testemunhos estudados, um ao sul da cidade de Joinville (26⒉'S, 4852'W) e outro próximo a São Leonardo (2742’S, 49॰09'W), indicaram um clima mais seco entre ca. 4900 e 4600 anos BP e um aumento da umidade entre 4600 e 3500 anos BP, mas não há indicações sobre mudanças de temperatura (Behling 1995). De todo modo, a proximidade entre a área de estudo e o limite meridional atual do mangue tornam improvável uma explicação puramente climática.
Por outro lado, variações significativas do nível do mar ocorreram neste período, as quais podem explicar o desaparecimento local do mangue.

Após uma queda significativa do nível relativo do mar durante o último máximo glacial (a cerca de 18.000 anos BP o mar estava 110-120 m abaixo do nível atual), o mar voltou a subir até atingir a cota atual em torno de 7000 anos BP. Durante o Holoceno, o nível continuou subindo, alcançou um máximo em torno de 5500 anos cal BP, para em seguida regredir progressiva e continuamente (Angulo et al. 2006).

$\mathrm{O}$ registro de mangue neste sambaqui, em torno de 4900 anos cal BP, situa-se logo depois do máximo holocênico, num momento em que o nível relativo do mar ainda estava significativamente mais alto do que o atual - a estimativa, para esta região, é de que o nível relativo do mar tenha estado, até ca. 4000 anos cal BP, entre 1 e 3 metros mais alto do que no presente (Angulo et al. 2006). Nestas condições, a paisagem local era bem diferente do que se conhece hoje.

Na configuração geomorfológica atual da área, não há condições favoráveis à instalação do mangue. Na época de construção do sítio, no entanto, durante o máximo transgressivo, a baía que aí existia pode ter oferecido tais condições devido à existência de uma zona de águas calmas, apresentando uma mistura de água doce, proveniente dos cursos d'água que nela desaguavam, e de água salgada, do mar. Posteriormente, a baixa do nível do mar e o fechamento da baía, dando origem às lagoas isoladas do mar por um cordão arenoso, teriam provocado o desaparecimento do mangue. 
Registro de mangue em um sambaqui de pequeno porte do litoral sul de Santa Catarina, Brasil, a cerca de 4900 anos cal BP, e considerações sobre o processo de ocupação do sítio Encantada-III.

Revista do Museu de Arqueologia e Etnologia, São Paulo, 19: 103-118, 2009.

A ocorrência de vegetação de mangue na região durante o período de ocupação sambaquieira é corroborada pela presença de camadas significativas de Ostrea sp em vários sambaquis da porção mais interna da laguna, sobretudo em Rio Caipora, Lajeado e Ilhotinha (28'24'28"S, 4857'51"W), os mais antigos da região, nos quais conchas de Ostrea foram datadas em $6590 \pm 60$ (7413-7171 anos cal BP), $5470 \pm 60(6199-5906$ anos cal BP) e $5270 \pm 60$ anos BP (5960-5658 anos cal BP), respectivamente. Nenhum fragmento de planta típica de mangue foi encontrado nas análises antracológicas do sambaqui Jabuticabeira-II (28॰35’25"S, 48.57’36"W), a cerca de $4 \mathrm{~km}$ do EncantadaIII, mas também nele a presença de ostras em áreas funerárias desde pelo menos ca. $2280 \pm 80$ anos BP (2362-1992 anos cal BP), inclusive exemplares portando marcas de fixação a raízes (Fig. 8), sugerem a ocorrência de mangue nas proximidades (Scheel-Ybert 2001; Bianchini 2008).

No entanto, embora seja um indício forte, a presença de ostras não é uma evidência indiscutível de ocorrência local de mangue, pois não se pode descartar a possibilidade de que tenham sido transportadas em âmbito regional, especialmente quando presentes em contexto funerário. $\mathrm{O}$ mesmo acontece com madeira de uso utilitário ou ritual, que devido a aspectos práticos ou simbólicos pode ser transportada a partir de distâncias relativamente longas (e.g. Bianchini et al. 2007; Bianchini 2008). Por outro lado, a lenha utilizada em fogueiras, ou seja, a madeira utilizada como combustível é sempre proveniente de um raio relativamente restrito no entorno do sítio (Vernet 1977; Chabal 1997; Scheel-Ybert 2000).

Outro resultado importante das análises antracológicas é que estas, associadas às datações obtidas, demonstram a existência de dois momentos distintos de ocupação do sítio. Embora amostras de apenas dois níveis artificiais tenham sido datadas, a pequena quantidade de carvões encontrada no sítio e a relativa similaridade taxonômica dos níveis 0-10 e 10$20 \mathrm{~cm}$ (zona II), de um lado, e $20-30$ e $30-40 \mathrm{~cm}$ (zona I), de outro, permitem levantar a hipótese de que os carvões de cada uma destas zonas corresponda a eventos relativamente contemporâneos entre si.

O primeiro momento de ocupação, datado em 4970-4830 anos cal BP, está relacionado à

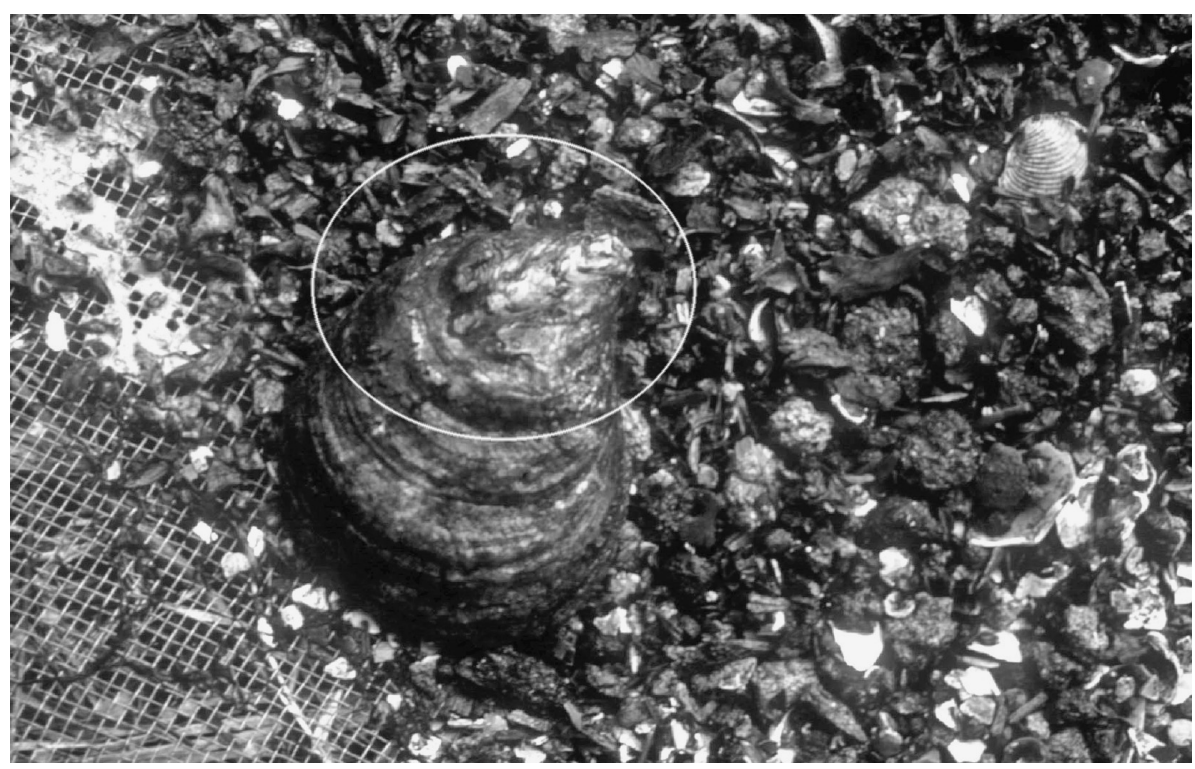

Fig. 8. Exemplar de Ostrea portando marca de fixação a raiz coletado numa área funerária do sambaqui Jabuticabeira-II (Locus 2, Trincheira T-18), datada de ca. 2362-1992 anos cal BP (Foto: Rita Scheel-Ybert). 
construção e ocupação do sítio propriamente dita. Não se sabe, até o momento, qual teria sido a função deste sambaqui. Os dados antracológicos não contribuem para esclarecer esta questão, mas eles descartam a possibilidade de que este seja um sítio de habitação, pois a raridade dos fragmentos de carvão, seu pequeno tamanho e sua baixa diversidade específica não apontam para um uso cotidiano. Os mesmos fatores permitem também sugerir que, qualquer que tenha sido a função do sítio, sua utilização não foi contínua no tempo, mas sim de curta duração.

O segundo momento, datado em 720-650 anos cal BP, é evidência de uma re-ocupação posterior do sítio, a qual, pelas mesmas razões expostas acima, foi provavelmente temporária.

A possibilidade de um evento de queimada ou paleoincêndio na superfície do sítio é improvável. A configuração geomorfológica da área, no limite entre uma zona de dunas com intensa movimentação eólica e uma planície pantanosa facilmente inundável não é favorável ao desenvolvimento da vegetação mais densa de mata de restinga identificada nas amostras antracológicas. Nesta área, a vegetação local se restringe a plantas herbáceas e sub-arbustivas, com alguns arbustos esparsos. Os lenhos que foram queimados sobre o sítio, consequentemente, não podem ser provenientes de uma vegetação que ocorresse na superfície do mesmo, mas foram para aí transportados, ainda que não necessariamente de muito longe.

Assim como no caso da amostra anterior, a raridade, pequeno tamanho e baixa diversidade de carvões não sugerem um uso cotidiano, mas muito provavelmente a utilização de uma ou poucas fogueiras durante um curto intervalo de tempo, o que é compatível com a hipótese de um acampamento. Considerando a possibilidade de que pelo menos alguns dos coquinhos e sementes associados a este momento de ocupação sejam efetivamente restos alimentares, este dado corroboraria a hipótese de um acampamento com fogueiras de uso culinário.

Este acampamento poderia estar relacionado com populações Je ou Guarani. A hipótese é fundamentada exclusivamente na cronologia, já que não existem até o momento outras indica- ções, sejam elas baseadas em vestígios arqueológicos ou arqueobotânicos. No entanto, as datações obtidas até o momento no quadro do projeto "Sambaquis e Paisagem" indicam que a ocupação sambaquieira desta região ocorreu entre cerca de 7600 e 1200 anos cal BP (De Blasis et al. 2007). Seguiram-se a ela ocupações Je e Guarani (De Blasis et al. 2007), de modo que o mais provável é que a ocupação datada de 720-650 anos cal BP seja relativa a um destes grupos.

\section{Conclusão}

Os dados antracológicos, associados às datações obtidas, apontam para a existência de dois períodos de ocupação no sítio, provavelmente de curta duração, sem evidências de atividades cotidianas nem do uso repetido do fogo, sendo o primeiro associado à construção do sítio por populações sambaquieiras e o segundo, possivelmente, a um acampamento de populações Je ou Guarani, que ocuparam a área posteriormente.

O entorno do sítio, nos dois períodos, era ocupado essencialmente por uma mata de restinga, provavelmente situada em direção ao interior. $\mathrm{O}$ registro antracológico também apresenta elementos que podiam pertencer tanto à restinga aberta quanto à vegetação típica de borda de lagoa. Os elementos de mangue são restritos ao primeiro período de ocupação.

No segundo período de ocupação, a presença de vestígios arqueobotânicos não lenhosos sugere a possibilidade de se tratar, pelo menos em parte, de restos alimentares vegetais.

Os resultados aqui apresentados são importantes em vários aspectos.

Do ponto de vista paleoambiental, eles demonstram a ocorrência de mangue há cerca de 4900 anos cal BP um pouco ao sul de seu limite atual de distribuição, indicando que sua área de distribuição, no passado, foi mais extensa do que é atualmente. $\mathrm{O}$ desaparecimento do manguezal nesta área pode ser explicado pela variação do nível relativo do mar. Variações climáticas e fatores antrópicos também podem ter influído na 
Registro de mangue em um sambaqui de pequeno porte do litoral sul de Santa Catarina, Brasil, a cerca de 4900 anos cal BP, e considerações sobre o processo de ocupação do sítio Encantada-III.

Revista do Museu de Arqueologia e Etnologia, São Paulo, 19: 103-118, 2009.

distribuição passada do mangue, mas outros estudos na região, assim como mais ao sul, ainda são necessários para verificar esta hipótese.

Do ponto de vista arqueológico, estes resultados (1) fornecem informações sobre a paisagem local, apresentando evidências diretas da ocorrência de mangue na própria área de implantação do sítio; (2) corroboram a estreita associação entre grupos sambaquieiros e o manguezal; (3) evidenciam o uso de madeira de mangue como combustível em sambaquis desta região; e (4) fornecem elementos interpretativos que podem auxiliar na compreensão do processo de ocupação do sítio.

\section{Agradecimentos}

Este trabalho foi realizado no quadro do projeto "Sambaquis e Paisagem: modelando a inter-relação entre processos culturais e naturais no litoral sul de Santa Catarina”, coordenado por Paulo De Blasis (MAE-USP), com suporte da Fundação de Amparo à Pesquisa do Estado de São Paulo-FAPESP. A primeira autora é Bolsista de Produtividade e contou com apoio financeiro do CNPq.

Os autores agradecem ao Dr. Jean-Pierre Ybert e à Dra. Veronica Wesolowski pela leitura crítica do manuscrito e por valiosas sugestões.

RITA SCHEEL-YBERT, R.; BIANCHINI, G.F.; DE BLASIS. P. Mangrove record in a small sambaqui from the southern Santa Catarina coast, Brazil, at circa $4900 \mathrm{cal}$ yrs BP, and considerations about the site Encantada-III occupation process. Revista do Museu de Arqueologia e Etnologia, São Paulo, 19: 103-118, 2009.

\begin{abstract}
Wood charcoal pieces of Avicennia sp, a typical and exclusive mangrove species, were retrieved from archaeological sediments dated of ca. 4900 years BP at sambaqui Encantada-III, Jaguaruna, Santa Catarina State. This site is localized slightly to the south of the present limit of mangrove distribution; the mangrove disappearance from this region is probably associated to variations in the relative sea level. These results corroborate the close association between sambaqui groups and the mangrove, and present direct evidence of the occurrence of this vegetation type close to the site implantation area and of the use of mangrove wood as fuel in sambaquis from this region. Moreover, anthracological data point to the existence of two periods of occupation in this site, probably of short duration, without evidence of quotidian activities. While the first period is associated to sambaqui populations, the second one is possibly related to Je or Guarani populations who inhabited the area subsequently.
\end{abstract}

Keywords: Sambaquis - Anthracology - Mangrove - Palaeoenvironment Holocene - Southern Brazilian coast.

\title{
Referências bibliográficas
}

ANGULO R.J.; LESSA G.C. \& SOUZA M.C.

2006 A critical review of mid- to late-Holocene sea-level fluctuations on the eastern Brazilian coastline. Quaternary Science Review, 25: 486-506.
BEHLING, $\mathrm{H}$.

1995 Investigations into the Late Pleistocene and Holocene history of vegetation and climate in Santa Catarina (S Brazil). Vegetation History and Archaeobotany, 4: 127-152. 
BIANCHINI, G.F.

2008 Fogo e Paisagem: evidências de práticas rituais e construção do ambiente a partir da análise antracológica de um sambaqui no litoral sul de Santa Catarina. Dissertação de Mestrado, Mestrado em Arqueologia do Museu Nacional, UFRJ. 200p.

BIANCHINI, G.F. ; SCHEEL-YBERT, R.; GASPAR, M.D.

2007 Estaca de Lauraceae em contexto funerário (sítio Jaboticabeira-II, Santa Catarina, Brasil). Revista do Museu de Arqueologia e Etnologia, São Paulo, 17: 223-229.

BLASCO, F.

1987 Réflexions sur le déterminisme des formations végétales tropicales. In: Cambon, G.; Richard, P.; Suc, J.-P. (Eds.) Palynologie et Milieux Tropicaux. Mémoires et Travaux de l'Institut de Montpellier, 17: 3-13.

BRADLEY, R.

1999 Paleoclimatology: Reconstructing Climates of the Quaternary. $2^{\text {nd }}$ edition. International Geophysics Series, Volume 68. Elsevier, Academic Press. 613p.

CHABAL, L.

1997 Forêts et sociétés en Languedoc (Néolithique final, Antiquité tardive): L'anthracologie, méthode et paléoécologie. Documents d'archéologie française, 63: 1-188.

CINTRÓN-MOLERO, G.; SCHAEFFER-NOVELLI, Y.

1992 Ecology and management of New World mangroves. In: Seeliger, U. (Ed.) Coastal communities of Latin America. San Diego, Academic Press: 233-258.

DE BLASIS, P.; FISH, S.K.; GASPAR, M.D. ; FISH, P.R.

1998 Some references for the discussion of complexity among the sambaqui moundbuilders from the southern shores of Brazil. Revista de Arqueologia Americana, 15: 75-105.

DE BLASIS, P.; KNEIP, A.; SCHEEL-YBERT, R.; GIANNINI, P.C.; GASPAR, M.D.

2007 Sambaquis e paisagem: dinâmica natural e arqueologia regional no litoral do sul de Santa Catarina. Revista de Arqueologia Sul-Americana, 1 (3): 29-61.

EASTOE, C.J.; FISH, S.; GASPAR, M.D.; LONG, A.

2002 Reservoir corrections for marine samples from the south Atlantic coast, Santa Catarina State, Brazil. Radiocarbon, 44 (1): 145-148.

GIANNINI, P.C.F.

1993 Sistemas Deposicionais no Quaternário Costeiro entre Jaguaruna e Imbituba, SC.
São Paulo, Instituto de Geociências, Universidade de São Paulo. Tese de Doutorado (ined.) 2v, 2 maps, 439p.

1998 Associações de fácies eólicas ativas na costa centro-sul de Santa Catarina. Anais da Academia Brasileira de Ciências, 70 (3): 696.

2002 Complexo lagunar centro-sul catarinense - valioso patrimônio sedimentológico, arqueológico e histórico. In: Schobbenhaus, C.; Campos, D.A.; Queiroz, E.T.; Winge, M.; Berbert-Born, M. (Eds.) Sítios Geológicos e Paleontológicos do Brasil. Brasília, DNPM: 213-222.

GIANNINI, P.C.F.; DE BLASIS, P.; SAWAKUCHI, A.O.; AMARAL, P.G.C.

2005 Processos e materiais geológicos e a construção de sambaquis no litoral sul de Santa Catarina. In: Congresso da Associação Brasileira de Estudos do Quaternário (ABEQUA), 10, Guarapari, ES. Anais... meio digital (cd). Guarapari, cód. 137.

GIANNINI, P.C.F.; SAWAKUCHI, A.O.; MARTINHO, C.T.; TATUMI, S.H.

2007 Eolian depositional episodes controlled by Late Quaternary relative sea level changes on the Laguna-Imbituba coast, South Brazil. Amsterdam, Marine Geology, 237 (2007): 143-168.

HUGHEN, K.; BAILLIE, M.G.L.; BARD, E.; BECK, J.W.; BERTRAND, C.J.H.; BLACKWELL, P.G.; BUCKS, C.E.; BURR, G.S.; CUTLER, K.B.; DAMON, P.E.; EDWARDS, R.L.; FAIRBANK, R.G.; FRIEDRICH, M.; GUILDERSON, T.P.; KROMER, B.; MCCORMAC, G.; MANNING, S.; RAMSEY, C.B.; REIMER, P.J.; REIMER, R.W.; REMMELE, S.; SOUTHON, J.R.; STUIVER, M.; TALAMO, S.; TAYLOR, F.W.; PLICHT VAN DER, J.; WEYHENMEYER, C.E.

2004 Marine 04 marine radiocarbon age calibration, 0-26 cal kyr BP. Radiocarbon, 46 (3): 1059-1086.

IBGE

2002 Mapa de Climas do Brasil. Instituto Brasileiro de Geografia e Estatística e Ministério do Planejamento, Orçamento e Gestão. In: <www.ibge.gov.br /home / geociencias/cartografia/default.shtm>. Acessado em 8 de agosto de 2007.

KLEIN, R.M.

1978 Mapa fitogeográfico do Estado de Santa Catarina. Itajaí: Superintendência do Desenvolvimento da Região Sul, Fundação de Amparo a Tecnologia e Meio Ambiente, Herbário Barbosa Rodrigues. 
Registro de mangue em um sambaqui de pequeno porte do litoral sul de Santa Catarina, Brasil, a cerca de 4900 anos cal BP, e considerações sobre o processo de ocupação do sítio Encantada-III.

Revista do Museu de Arqueologia e Etnologia, São Paulo, 19: 103-118, 2009.

SCHAEFFER-NOVELLI, Y.; CINTRÓN-MOLERO, G.; ADAIME, R.R.; CAMARGO, T.M.

1990 Variability of mangrove ecosystems along the Brazilian coast. Estuaries, 13 (2): 204-218.

SCHAEFFER-NOVELLI, Y.; CINTRON-MOLERO, G.; SOARES, M.L.G.; DE ROSA, T.

2000 Brazilian mangroves. Aquatic Ecosystem Health and Management, 3: 561-570.

SCHEEL-YBERT, R.

1999 Paleoambiente e paleoetnologia de populações sambaquieiras do sudeste do Estado do Rio de Janeiro. Revista do Museu de Arqueologia e Etnologia, São Paulo, 9: 43-59.

2000 Vegetation stability in the southeastern Brazilian coastal area from 5500 to 1400 $14 \mathrm{C}$ yr BP deduced from charcoal analysis. Review of Palaeobotany and Palynology, 110: 111-138.

2001 Vegetation stability in the Brazilian littoral during the late Holocene: anthracological evidence. Revista Pesquisas em Geociências, 28 (2): 315-323.

SCHEEL-YBERT, R., DIAS, O.F.

2007 Corondó: Palaeoenvironmental reconstruction and palaeoethnobotanical considerations in a probable locus of early plant cultivation (south-eastern Brazil). Environmental Archaeology, 12: 129-138.

SCHEEL-YBERT, R., EGGERS, S., WESOLOWSKI, V., PETRONILHO, C.C., BOYADJIAN, C.H., DE BLASIS, P.A.D., BARBOSA-GUIMARÃES, M.; GASPAR, M.D.

2003 Novas perspectivas na reconstituição do modo de vida dos sambaquieiros: uma abordagem multidisciplinar. Revista de Arqueologia, SAB, 16: 109-137.

SCHEEL-YBERT, R., KLÖKLER, D., GASPAR, M.D., FIGUTI, L.

2005/2006 Proposta de amostragem padronizada para macrovestígios bioarqueológicos: antracologia, arqueobotânica, zooarqueologia. Revista do Museu de
Arqueologia e Etnologia, São Paulo, 15-16: 139-163.

SCHEEL-YBERT, R., CARVALHO, M.A., GONÇALVES, T.A.P., SCHEEL, M., YBERT, J.P.

2006 Coleções de referência e bancos de dados de estruturas vegetais: subsídios para estudos paleoecológicos e paleoetnobotânicos. Arquivos do Museu Nacional, Rio de Janeiro, 64: 255-266.

SDM

2002 Plano Integrado de Recursos Hídricos da Bacia Hidrográfica do Rio Tubarão e Complexo Lagunar. Governo do Estado de Santa Catarina. Secretaria de Estado do Desenvolvimento Urbano e Meio Ambiente/SDM.

SILVEIRA, F.

1937 Mangrove. Rodriguésia, 3 (10): 131-154.

STUIVER, M.; REIMER, P.J.; REIMER R.

2008 Calib Radiocarbon Calibration. version 5.0.2html. In: <http://calib.qub.ac.uk/ calib/>

VERNET, J.L.

1977 Les macrofossiles végétaux et la paléoécologie du Pléistocène. Bulletin de l'Association Française pour l'étude du Quaternaire, suppl., 47: 53-55.

VERNET, J.L.; BAZILE, E.; EVIN, J.

1979 Coordination des analyses anthracologiques et des datations absolues sur charbon de bois. Bulletin de la Société de Préhistoire de France, 76 (3): 76-79.

WALSH, G.E.

1974 Mangroves: a review. In: Reimhold, R.; Queen, W. (Eds.) Ecology of halophytes. New York: Academic Press.

YBERT, J.P.; BISSA, W.M.; CATHARINO, E.L.M.; KUTNER, M.

2003 Environmental and sea-level variations on the southeastern Brazilian coast during the Late Holocene with comments on prehistoric human occupation.

Palaeogeography, Palaeoclimatology, Palaeoecology, 189: 11-24. 